\title{
Understanding Organisational Effectiveness Through Sustainable Human Relations Approach:
} The Role of Empowerment Climate in
Selected Industrial Establishments

\author{
Simanchala Das, Koneru Lakshmaiah Education Foundation (Deemed), India \\ (iD) https://orcid.org/0000-0001-6230-0461 \\ Biswajit Acharjya, Koneru Lakshmaiah Education Foundation (Deemed), India
}

\begin{abstract}
Organisational effectiveness undoubtedly depends on well-designed human resource practices which embrace vibrant industrial relations. The relations that exist between superior and subordinates in industrial establishments are mostly contingent upon the degree of autonomy in the decision-making process. As autonomous decision making is an integral part overall empowerment strategy, the climate that fosters trust, creativity, competitiveness, and proactive problem-solving intention tend to influence the employee perception towards improved organisational effectiveness. Earlier studies have established the direct relationship between psychological empowerment and to a certain extent in combination with structural empowerment variables and organisational effectiveness in a specific context. But the present research seeks to study the role of empowerment climate as a moderating variable for the aforesaid relationship which would ultimately bring about the effectiveness in the selected industrial establishments.
\end{abstract}

\section{KEYWORDS}

Employee Empowerment, Empowerment Climate, Organisational Effectiveness, Psychological Empowerment, Structural Empowerment

\section{INTRODUCTION}

Organisational sustainability is one of the critical factors through which organisations particularly industrial organisations achieve competitive advantage in the changed business environment. It can be attained through continuous improvement in human relations, technological interventions and above all strategic goal internalisation. Further, it is acknowledged that understanding the worth of human resources and its management is the key to improve the business performance (Kamble et al., 2020). Besides, the autonomous work processes also help organisation to attain the competitive advantage over others. In the globalised era, most of the organisations are resorting to the practice of employee empowerment as a tool to enhance organisational performance (Zuñiga et al., 2020). This trend has called for a changed perspective of employee empowerment as an important measure to enhance organisational effectiveness. In other words, the concept has received wide acceptance by the 
managers mainly because of its contribution to managerial and organisational effectiveness. Although attempts have been made to find out mediating or moderating variables in such a relationship, no concrete evidence has yet been found on this aspect (Lee and Kim, 2020).

Further, empirical studies have confirmed that 'empowerment climate' and 'psychological empowerment' are distinctive elements (Seibert et al., 2004; Wang et al., 2013), but the former is perceived as an important moderator that significantly influence the employee empowerment process. Further, Lin, et al., (2020) found team empowerment climate as an antecedent of team empowerment but it might have a moderating effect. Furthermore, it is also found that an adequate empowerment climate could result in trust, information sharing autonomy and accountability in the team (Randolf, 1995). 'Information sharing' is the sharing of information about organisation with employees. Similarly, autonomy as an organisational practice helps employees to demonstrate their behaviour autonomously. In another study, it is held that team accountability occurs when teams become the performance and decision-making mechanisms (Seibert et al, 2004). Thus, the previous literature which tried to focus on this aspect seems to have limited distinctive contribution to the concept of empowerment climate as some of them only emphasised on the team empowerment climate.

The rest of the section is organised as follows. Followed by introduction, Section 2 provides a brief review of relevant literature. The conceptual framework of the study and the hypothesis framing is discussed in Section 3. The methodology carried out in the research is explained in Section 4. Section 5 discusses analysis and interpretation of the result. Discussion on findings, limitation and scope of future research is elucidated in Section 6. Finally, Section 7 discusses the conclusion of this study.

\section{LITERATURE REVIEW}

This section lists out the relevant literature pertaining to the study. The main aim is to identify the key variables of the study based on the research gap. To this end, it elucidates various concepts such as psychological empowerment, structural empowerment, organisational effectiveness, and empowerment climate.

Psychological empowerment is one of the key research interests in recent studies pertaining to organisational culture and development. It deals with the individual confidence building through collection of powerfulness or eliminating the feeling of powerlessness from the individual point of view. It generates through self-efficacy by the way of organisational practices and sharing informal information. Few studies linked Organisation development culture with Total Quality Management (TQM) in the healthcare organisation (Gozikara et al., 2018). Additionally, it examined the mediating role of top management leadership and employee empowerment. The study employed structural equation modelling (SEM) and found a significant positive influence of development culture towards TQM. Further it is evident that the relationship is mediated by top management leadership but not by the employee empowerment. Similarly, the direct as well as indirect influence of ethical leadership on employee's turnover intention is studied in the banking sector by considering psychological empowerment and organisational identification as mediating effect (Sulfan et al., 2020). The result showed that ethical leadership has negative effect on manager's turnover intention. But it shows a partial mediation effect. Further, Megan et al., (2018) studied the relationship between structural as well as psychological empowerment of nurses and the clinical leadership behaviour in an emergency healthcare department. The results confirmed that the nurses demonstrated their clinical leadership behaviour, even though their sense of psychological empowerment is moderately affecting the behaviour.

Psychological empowerment can be measured through various sub-dimensions. Thomas and Velthouse (1990) substantiated Conger's model with intrinsic task motivation that manifested psychological empowerment with four sub-dimensions such as impact, competence, meaningfulness, and choice. Similarly, Spreitzer (1995) talked about the multidimensionality of psychological empowerment having four sub-dimensions such as meaning, competence, self-determination, and 
impact. Further, Menon (1999) devised a reliable psychometric based empowerment model having three sub-dimensions. Likely, Menon and Pethe (2002) examined the role of climate and leader empowering behaviour on psychological empowerment. Further, Sally (2004) also investigated the role of empowerment as a mediator between climate and job satisfaction. Moreover, Kaur (2013) investigated the impact of structural and psychological empowerment on organisational effectiveness. Considering the above literature, the present study used four critical sub-dimensions for measuring psychological empowerment such as meaning, competence, self-determination, and impact. Elharakany et al. (2018) found that the performance of higher educational institutions depends upon effective use of information and communication technology, empowering employees with the help of sustainable human relations policies and practices of the organisation is another critical factor for achieving the organisational effectiveness. Hence, the study pertaining to structural empowerment is gaining research interest in recent days. Yurumazoglu et al., (2019) studied the relationship between structural empowerment, supervisor's co-worker's incivility, and their intention to leave the organisation. The study conducted a cross sectional correlation study on selected nurses and found that structural empowerment had both direct and indirect effect. Similarly, the association between workforce diversity and firm performance by taking structural empowerment as a moderator is also studied (Lee and Kim, 2019). Further, few studies tested the role of hardness in the relationship between structural empowerment, psychological empowerment, and burnout (Carlos et al., 2017). The study analysed 210 middle level managers response and obtained burnout is indirectly affected by structural empowerment through psychological empowerment moderated by hardness. It also highlighted that the indirect effect was only significant medium and high hardness. Furthermore, Amor et al., (2020), studied the effect of structural empowerment in the context of transformational leadership and work engagement. The study has revealed a partial mediation of structural empowerment between transformational leadership and work engagement in the tourism industry. Abdullah \& Iqbal (2020) further examined the impact of paternal human resource practices on the outcomes of employee behaviour.

Organisational effectiveness deals with the efficiency of the organisation in the direction of achieving the desired goal and objective. The effectiveness of the organisation can be attained through various factors. Hence, research has been carried out in the direction of finding these factors. Recent studies have found a significant positive relation between high performance work systems and organisational ambidexterity (Chang, 2016). Shukla, et al., (2019) explored the criteria for a sustainable performance decision model in marble industry. Kadeem et al., (2017) used system dynamics approach in work system design exploring management and organisational factors. Similarly, Quinn and Cameron (1983), in their study, tried to design an organisational effectiveness criterion scientifically. Further, Dumblekar and Sharma (2001) studied the roles of leadership in highperformance organisation in the banking sector. Similarly, the effectiveness of research organisations by developing a criterion is also studied (Jordan, 2003). Further, Priyadarshini and Venkatapathy (2003) in their study identified important factors affecting the effectiveness in different categories of banks. In the same way relationship between psychological empowerment and organisational effectiveness is studied in banking sector (Sharma and Kaur, 2011).

Empowerment climate has limited application in studies pertaining to organisational effectiveness. Recent studies examined the impact of empowerment climate on safety and quality of food and financial performance in a national level food chain restaurant (Roseman, 2017). The study found a direct and indirect relationship amongst psychological empowerment, food safety, food quality and financial performance. Further, Lin and Ling (2017) examined three empowerment levels of empowerment climate such as organisational, departmental, and individual. The study found the relationship among three levels with the influence of empowerment climate. Moreover, Alexander et al., (2019) examined the mediating role of decision process in the relationship between environmental dynamism, advise seeking. The study also tested the moderating effect of empowerment climate and concluded that there was close association between individual level and organizational level information processing. Further, Seibert et al., (2004) in their study tried to establish the relationship between empowerment 
climate and psychological empowerment. Thus, the empowerment climate as a moderator has not been given appropriate importance in the above studies. Simultaneously, it has not included as a linkage variable between employee empowerment and organisational effectiveness. The following research questions (RQ) and the related presumptions have been formulated based on the above studies.

\subsection{Research Questions}

RQ1: Does structural empowerment positively associate with organisational effectiveness?

RQ2: Does psychological empowerment positively affect organisational effectiveness?

RQ3: Does empowerment climate significantly influence employee empowerment to improve organisational effectiveness?

\subsection{Research Objectives}

The study has the following broad objectives:

1. To examine the relationship between psychological empowerment and organisational effectiveness.

2. To investigate the relationship between structural empowerment and organisational effectiveness.

3. To study the moderating effect of empowerment climate on the relationship between employee empowerment and organisational effectiveness.

\section{RESEARCH HYPOTHESIS}

The research hypothesis of this study is a tentative possibility of the research outcome. The assumptions have been framed based on the significant relations that exist in previous literature. Moreover, it provides the tentative outcome between the variables of interest. The following are descriptions about the variables of the study and their possible effects on the outcome variable.

\subsection{Psychological Empowerment}

Psychological empowerment empowers the employees to take part in the organisational decision making. It motivates individual to forego the inactive attitudes and to take active participation in taking risk and innovate organisational decision. The meaning and competence are two critical factors of psychological empowerment that found to have strong positive influence on job satisfaction, and intention of career progression (Spreitzer, 1997). Similarly, Kraimer et al. (1999) found that selfdetermination and impact do predict organisational commitment. Hence, we considered meaning, competence, self-determination, and impact are four dimensions of psychological empowerment. But there is not much evidence of a single dimension which relates to psychological empowerment. Hence the hypotheses of the variable is formulated as follows.

$\mathbf{H}_{\mathbf{1}}$ : There is a significant positive influence of psychological empowerment on organisational effectiveness.

\subsection{Structural Empowerment}

Structural empowerment makes the organizations standardize that in turn plays a significant positive role in empowering behaviour of the employees. But most organisations face lack of consensus regarding the structures and practices of the organisation. Limited research has carried out in the direction of mere identification of organizational practices that, if used, could lead to empowered employees. When information is shared between the user and the organization admin, security plays a key role in any business organization in terms of privacy. (Auxilia, et al.) It is evident from 
the previous studies that information sharing, power, rewards have positive outcomes for even organisations in terms of improvements in QWL, the quality of products and customer service and reduced employee turnover. (Lawler et al., 2001). Thus, based on the above literature, the following proposition is formulated.

$\mathbf{H}_{2}$ : There is a significant positive influence of structural empowerment on organisational effectiveness.

\subsection{Empowerment Climate}

Empowerment climate is found to have a group orientation and is quite distinct from psychological empowerment as the former is incorporated in many HR policies and practices (Seibert et al, 2004). Some of the researchers such as Spreitzer (1997) and Kaur (2013) have taken climate and culture as a dimension of structural empowerment. But in this study empowerment climate was presumed to have an important moderating role in bringing about organisational effectiveness. Hence the following presumption is made.

$\mathbf{H}_{3}$ : The effect of psychological empowerment on the perception of organisational effectiveness is accentuated with favourable empowerment climate in the organisation.

$\mathbf{H}_{4}$ : The effect of structural empowerment on the perception of organisational effectiveness is accentuated with favourable empowerment climate in the organisation.

Based on the above literature and hypothesis the conceptual framework of this study is well depicted in Figure 1.

\section{RESEARCH METHODOLOGY}

This section explains the detail outline of the research pertaining to organisational effectiveness and its causal factors in the selected PSEs of India. The study is descriptive in nature where well validated concepts such as structural empowerment, psychological empowerment, empowerment climate, and organisational effectiveness are used as main variables of the study. Further, each variable consists of various sub-dimensions that identified from the literatures. Structural empowerment encompasses seven sub-dimensions such as locus of control, self-esteem, role clarity, autonomy, information communication, reward system, and skill and knowledge. Similarly, psychological empowerment has four sub-dimensions such as meaning, competence, self-determination and impact. Moreover, organisational effectiveness embodies four sub-dimensions such as human relation, open system, rational goal, and internal process. Empowerment climate is used as single variable consisting of various factors such as trust, information sharing, support, competitiveness, innovation and problem solving. The study segregated empowerment climate into two categories of favourable and unfavourable climate. For better visualisations the variables for the study and the notations are presented in Table 1.

The research is mainly quantitative in nature where primary survey is undertaken in Indian PSEs. Initially a structured questionnaire is adopted based on the selected variables. The data was collected using convenience sampling technique. The PEQ of Spreitzer (1996) was used for framing questionnaire of the variable psychological empowerment. A total of 12 items have been used for the 4 different dimensions such as meaning, competence, self-determination, and impact. Similarly, the modified form of structural empowerment questionnaire was adapted from Kaur (2013) who used around 50 statements for the selected variables like individual-centric, job centric and organisation centric. But for this study, 28 items have been adopted for over 7 dimensions such as locus of control, self-esteem, role clarity, autonomy, information \& communication, reward system, skills $\&$ knowledge. It is considered after discussing with a team of experts and a thorough review of the existing literature. A self-designed 15 item questionnaire was also administered for this study. A 28- 


\section{Figure 1. Conceptual framework}

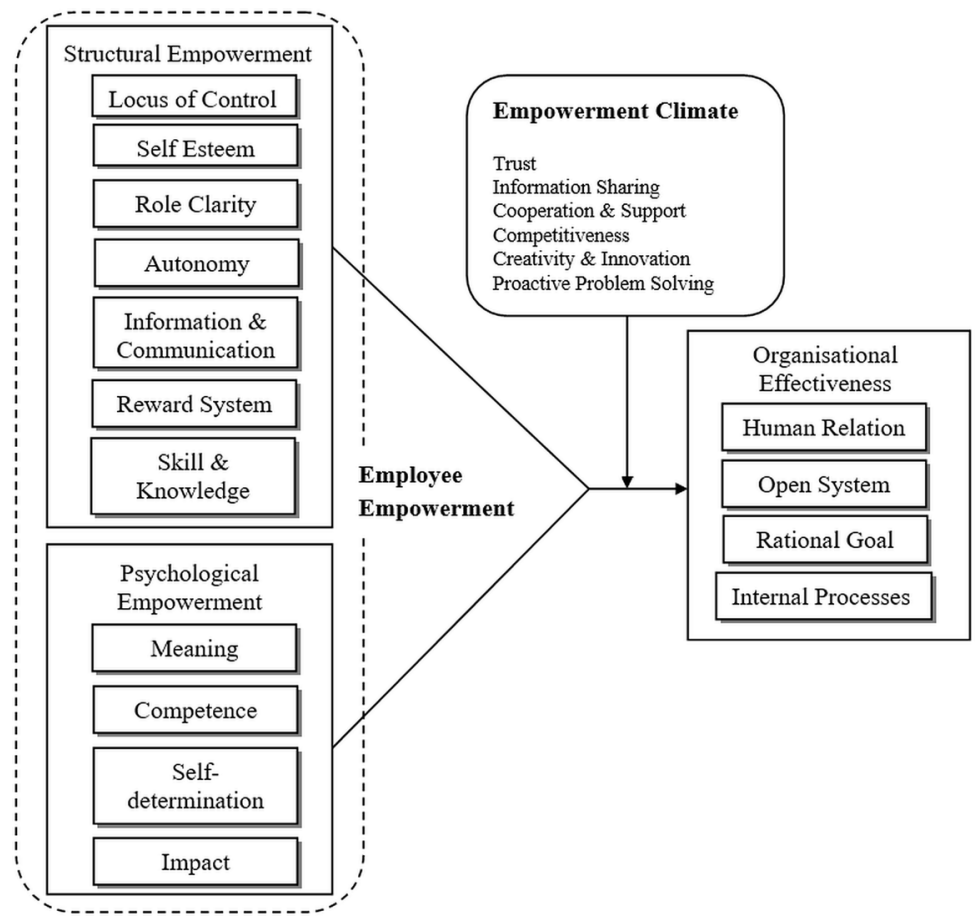

Table 1. Variables and notations

\begin{tabular}{|c|c|c|c|c|c|}
\hline Variables & $\begin{array}{c}\text { Sub- } \\
\text { variables }\end{array}$ & Notation & Variables & Sub-variables & Notations \\
\hline \multirow[t]{7}{*}{$\begin{array}{l}\text { Structural Empowerment } \\
\qquad\left(a_{1}\right)\end{array}$} & $\begin{array}{c}\text { Locus of } \\
\text { Control }\end{array}$ & $a_{11}$ & \multirow[t]{4}{*}{$\begin{array}{c}\text { Psychological } \\
\text { Empowerment }\left(a_{2}\right)\end{array}$} & Meaning & $a_{21}$ \\
\hline & Self-Esteem & $a_{12}$ & & Competence & $a_{22}$ \\
\hline & Role Clarity & $a_{13}$ & & $\begin{array}{c}\text { Self- } \\
\text { determination }\end{array}$ & $a_{23}$ \\
\hline & Autonomy & $a_{14}$ & & Impact & $a_{24}$ \\
\hline & $\begin{array}{l}\text { Inf. and } \\
\text { comm. }\end{array}$ & $a_{15}$ & \multirow[t]{4}{*}{$\begin{array}{c}\text { Organisational } \\
\text { Effectiveness }\left(a_{3}\right)\end{array}$} & $\begin{array}{l}\text { Human } \\
\text { Relation }\end{array}$ & $a_{31}$ \\
\hline & $\begin{array}{l}\text { Reward } \\
\text { System }\end{array}$ & $a_{16}$ & & Open System & $a_{32}$ \\
\hline & $\begin{array}{c}\text { Skill \& } \\
\text { Knowledge }\end{array}$ & $a_{17}$ & & Rational Goal & $a_{33}$ \\
\hline \multicolumn{2}{|c|}{ Empowerment Climate } & $a_{4}$ & & $\begin{array}{l}\text { Internal } \\
\text { Process }\end{array}$ & $a_{34}$ \\
\hline
\end{tabular}


item questionnaire called as organisational effectiveness questionnaire as validated by Kaur (2013) was used for addressing the 4 sub-dimensions such as human relations, rational goal, open systems and internal process) models based on the 'competing values approach' (Quinn and Rohrbaugh, 1983). The 5-point Likert Scale was considered to measure all the above question items. The details of the questionnaire and its adopted sources are presented in Table 2 and Table 3.

A pilot study was conducted to assess validity on a sample consisted of 160 individuals selected from the population. Their suggestions were incorporated before administering the final form of the questionnaire. The final structured questionnaire was distributed among 450 employees of which 413 responses were finally received. Further 55 responses were omitted considering the missing and unreliable information. The final empirical study is conducted by considering 358 sample populations. The reliability of all the above scale items presented in Table 2 and Table 3 was tested using Cronbach's Alpha formula as presented in Equation-1, where $n$ is the number of items of each variable, $\sigma_{i}^{2}$ is the variance of single item and $\sigma_{j}^{2}$ is the variance of sum of all item score:

$$
\text { Cronbach's alpha }(\alpha)=\frac{n}{n-1} \times\left(1-\frac{\sum_{i=1}^{n} \sigma_{i}^{2}}{\sigma_{j}^{2}}\right)
$$

The value of Cronbach's alpha was found to be greater than 0.7 hence it is satisfactory as per the reliability criteria. The Cronbach value for all the variables are presented in Table 4.

\section{EMPIRICAL ANALYSIS}

This section explains details of the empirical studies carried out by considering final 358 sample data for identifying the factors influencing the organisational effectiveness. The key statistical measures such as correlation and regression analysis are performed to examine the details of the empirical analysis. The correlation analysis is used to find significant association between the variables. However, regression analysis is performed to identify the impact of psychological empowerment and structural empowerment towards the organisational effectiveness. Also, the same analysis is used for identifying the moderating effect of empowerment climate on both psychological and structural empowerment for improving the organisational effectiveness.

Initially, the association and impact of psychological empowerment and organisational effectiveness is analysed by using correlation and regression as follows. The Pearson's correlation coefficients between psychological empowerment and organisational effectiveness is presented in Table 5.

From Table 5 it is found that psychological empowerment and organisational effectiveness are found to have strong positive correlation $(\mathrm{r}=0.409, \mathrm{p}<0.001)$. A relatively strong relationship is demonstrated between the competence dimension and internal process model $(r=0.577, \mathrm{p}<0.001)$. Table 6 depicts that the four components of psychological empowerment as mentioned in the Table significantly predict organisational effectiveness. Self-determination has the highest influence (Standardized Coefficients $=0.369$ ) and competence (Standardized Coefficients $=0.108$ ) has the lowest influence on organisational effectiveness.

Similarly, the correlation analysis is carried out between the sub variables of both organisational effectiveness and structural empowerment is depicted in Table 7.

From Table 7 it is clear that the sub variables of organisational effectiveness and structural empowerment are having strong positive relations. The overall correlation between two variables are also found strong significant positive $(\mathrm{r}=0.304, \mathrm{p}=0.000)$. Above all it is also reveals that correlation is 
International Journal of System Dynamics Applications

Volume 10 • Issue 2 • April-June 2021

Table 2. Details of the questionnaire and scale items

\begin{tabular}{|c|c|c|}
\hline Notations & Questionnaire Details & Sources \\
\hline \multirow{3}{*}{$a_{11}$} & Responsible for changing what I do not like. & \multirow[t]{3}{*}{ Kaur (2013) } \\
\hline & Promotion depends on my ability and effort. & \\
\hline & Experience is most important in an organization & \\
\hline \multirow{3}{*}{$a_{12}$} & Like and accept myself right now, even as I grow & \multirow[t]{3}{*}{ Kaur (2013) } \\
\hline & Feel equal value to the other people regardless performance. & \\
\hline & Do not dominate others or allow others to dominate. & \\
\hline \multirow{4}{*}{$a_{13}$} & Clear about priorities in my role task. & \multirow[t]{4}{*}{ Kaur (2013) } \\
\hline & Clear about what my senior officers expect from me. & \\
\hline & Clear about rules, regulations and procedures relevant to me. & \\
\hline & Clear cut idea about my authority. & \\
\hline \multirow{5}{*}{$a_{14}$} & I can decide when to do particular work activities. & \multirow[t]{5}{*}{ Kaur (2013) } \\
\hline & I am allowed to decide what methods to use for my job. & \\
\hline & I have control over the scheduling of my work. & \\
\hline & I have control over what I am supposed to accomplish. & \\
\hline & I have opportunity to solve problems faced during my work. & \\
\hline \multirow{4}{*}{$a_{15}$} & Full knowledge about my organization's long-term goals. & \multirow[t]{4}{*}{ Kaur (2013) } \\
\hline & I am told about my departments' ongoing plans periodically. & \\
\hline & Fully aware about my departments' performance in 5 years. & \\
\hline & I can always approach those who are experts on the subject. & \\
\hline \multirow{6}{*}{$a_{16}$} & People are very clear about how performance is measured. & \multirow[t]{6}{*}{ Kaur (2013) } \\
\hline & My boss discusses my job with me very clearly. & \\
\hline & My boss counsels' improvement about my target. & \\
\hline & The performance appraisal system is well defined. & \\
\hline & People always recognized for a job, which is very well done. & \\
\hline & Performance is always communicated through a written note. & \\
\hline \multirow{3}{*}{$a_{17}$} & Special efforts are made to assess employees need training. & \multirow[t]{3}{*}{ Kaur (2013) } \\
\hline & The organization supports me to upgrade my skills. & \\
\hline & Organization organizes programmes to enhance the skills. & \\
\hline \multirow{3}{*}{$a_{21}$} & The work I do is very important to me & \multirow[t]{3}{*}{ Spreitzer (1995) } \\
\hline & My job activities are personally meaningful to me. & \\
\hline & The work I do is meaningful to me. & \\
\hline \multirow{3}{*}{$a_{22}$} & I am confident about my ability to do my job. & \multirow[t]{3}{*}{ Spreitzer (1995) } \\
\hline & I am self-assured about my capabilities in work activities. & \\
\hline & I have mastered the skills necessary for my job & \\
\hline \multirow{3}{*}{$a_{23}$} & I have significant autonomy in determining how I do my job. & \multirow[t]{3}{*}{ Spreitzer (1995) } \\
\hline & I can decide on my own how to do my work. & \\
\hline & I have considerable freedom in how to do my job. & \\
\hline \multirow{3}{*}{$a_{24}$} & My impact on what happens in my department is large. & \multirow[t]{3}{*}{ Spreitzer (1995) } \\
\hline & I have a great deal of control over my department. & \\
\hline & I have significant influence in my department. & \\
\hline
\end{tabular}


Table 3. Details of the questionnaire and scale items (Cont.)

\begin{tabular}{|c|c|c|}
\hline Notations & Questionnaire Details & Sources \\
\hline \multirow{8}{*}{$a_{31}$} & I give suggestions for the decisions, not affect my work area. & \multirow{8}{*}{$\begin{array}{l}\text { Quinn and } \\
\text { Rohrbaugh (1983) }\end{array}$} \\
\hline & Employees are given periodic feedback to improve. & \\
\hline & Employee suggestions are valued. & \\
\hline & Sufficient organizational support for development of skills. & \\
\hline & Proper grievance redressal procedure in the organization. & \\
\hline & Enough managerial support for managing work and home. & \\
\hline & Most policies of the organization are people friendly. & \\
\hline & Incentive for employees to discuss with their superiors. & \\
\hline \multirow{5}{*}{$a_{32}$} & The mgmt's attempts to be well informed about competitors. & \multirow{5}{*}{$\begin{array}{l}\text { Quinn and } \\
\text { Rohrbaugh (1983) }\end{array}$} \\
\hline & Improved infrastructure to meet customer demands. & \\
\hline & Regular surveys to check customer satisfaction. & \\
\hline & Survey findings are discussed and actions taken. & \\
\hline & Service quality is considered most important. & \\
\hline \multirow{10}{*}{$a_{33}$} & My organization has a mission statement & \multirow{10}{*}{$\begin{array}{l}\text { Quinn and } \\
\text { Rohrbaugh (1983) }\end{array}$} \\
\hline & The mission statement is known to and is understood by all & \\
\hline & The org. uses mission statement for determining success. & \\
\hline & Strategic plan is in tune with its mission statement. & \\
\hline & Annual action plans consistent with its mission. & \\
\hline & Action plans indicate the deadline for achievement. & \\
\hline & Annual plan is continuously monitored. & \\
\hline & Corrective actions are taken based on monitoring. & \\
\hline & Organisational goals as targets for employees. & \\
\hline & Systematic approach for identifying opportunities. & \\
\hline \multirow{6}{*}{$a_{34}$} & Clear-cut policies for resource allocation known to all. & \multirow{6}{*}{$\begin{array}{l}\text { Quinn and } \\
\text { Rohrbaugh (1983) }\end{array}$} \\
\hline & The managers are willing to take tough decisions. & \\
\hline & Line manager's decisions are consistent with corporate values. & \\
\hline & Routine processes are simple and uncomplicated. & \\
\hline & Managers can be called people friendly. & \\
\hline & Degree of transparency is high in organisational comm. & \\
\hline
\end{tabular}


Table 3. Continued

\begin{tabular}{|c|c|c|}
\hline Notations & Questionnaire Details & Sources \\
\hline \multirow{14}{*}{$a_{4}$} & Excellent communication about organizational information. & \multirow[t]{14}{*}{ Self-Designed } \\
\hline & The employees are willing to share information. & \\
\hline & The work I do is challenging and stimulating. & \\
\hline & High degree of transparency in org communication. & \\
\hline & The work I do is challenging and stimulating. & \\
\hline & Enough freedom to generate and implement new ideas & \\
\hline & Creative and innovative behaviour is always encouraged & \\
\hline & I am expected to be open about my feelings about the org. & \\
\hline & Employees are always cooperative and eager to support others. & \\
\hline & There is a feeling of competitiveness amongst the employees. & \\
\hline & Trusted to carry out without the direction of supervisor. & \\
\hline & High value is placed on trust between superior and subordinate. & \\
\hline & It maintains good relationship with vendors and suppliers. & \\
\hline & Able to identify and resolve the problems before they emerge. & \\
\hline
\end{tabular}

found to be very strong between autonomy and open system. $(r=0.420, p<0.001)$. Further, regression analysis is carried out to evaluate significant impact of sub-dimensions of structural empowerment towards the dependent variable organisational effectiveness and is presented in Table 8.

From Table 8 it shows that all the seven components of structural empowerment significantly predict organisational effectiveness. All the variables are significant and have a 27.9 percent variation. In this Table, autonomy is found to have the highest influence (Standardized Coefficients $=0.282$ ) and locus of control has the lowest influence (Standardized Coefficients $=0.043$ ).

Further, to study the moderating role of empowerment climate on the link between psychological empowerment and organisational effectiveness, the mid-value split method is used. It identifies a mid-value of 38 from the sum of scale value of 75 that in turn was used to split the data into two different data sets, namely, unfavourable empowerment climate $(<=38)$ and favourable empowerment climate $(>38)$. The mathematical representation splitting the variable is presented below in Equation 2. Where $N$ represents sum of scores of items and $a_{x i}$ is the items of the variables:

$$
\begin{aligned}
& N=\sum_{i=1}^{n} a_{x i} \\
& N=\left\{\begin{array}{c}
\text { Unfavourable if } 0<N \leq 38 \\
\text { Favourable if } 38<N \leq 75
\end{array}\right\}
\end{aligned}
$$

The moderating role of empowerment climate on the link between psychological empowerment and organisational effectiveness for the unfavourable empowerment climate is presented in Table 9. Similarly, the moderating role of empowerment climate on the link between psychological empowerment and organisational effectiveness for the favourable empowerment climate is presented in Table 10. 
Table 4. Reliability analysis

\begin{tabular}{|l|l|l|l|}
\hline \multicolumn{1}{|c|}{ Notation } & \multicolumn{1}{|c|}{ Cronbach's Alpha } & \multicolumn{1}{c|}{ Cronbach's Alpha } \\
\hline$a_{11}$ & 0.823 & $a_{21}$ & 0.921 \\
\hline$a_{12}$ & 0.777 & $a_{22}$ & 0.943 \\
\hline$a_{13}$ & 0.741 & $a_{23}$ & 0.897 \\
\hline$a_{14}$ & 0.811 & $a_{24}$ & 0.903 \\
\hline$a_{15}$ & 0.868 & $a_{31}$ & 0.884 \\
\hline$a_{16}$ & 0.833 & $a_{32}$ & 0.911 \\
\hline$a_{17}$ & 0.791 & $a_{33}$ & 0.865 \\
\hline$a_{4}$ & 0.756 & $a_{34}$ & 0.831 \\
\hline
\end{tabular}

Thus, Table 9 clearly shows that all the variables are found to be significant and have a 10.6 percent variation in the organisational effectiveness scores. Two important components of psychological empowerment are not significant in predicting organisational effectiveness e.g. meaning and selfdetermination. Similarly, Table 10 reveals that all the components are found to be statistically significant and have a 79.9 percent change in the organizational effectiveness scores.

The moderating role of empowerment climate on the link between structural empowerment and organisational effectiveness for the unfavourable empowerment climate is presented in Table 11.

Table 5. Pearson's correlation coefficients between psychological empowerment and organisational effectiveness

\begin{tabular}{|c|c|c|c|c|c|}
\hline & $a_{31}$ & $a_{32}$ & $a_{33}$ & $a_{34}$ & $a_{3}$ \\
\hline$a_{21}$ & $0.216^{* *}$ & $0.258 * *$ & $0.207 * *$ & $0.318^{* *} *$ & $0.591^{* *}$ \\
\hline$a_{22}$ & $0.189 * *$ & $0.577 * *$ & $0.218 * *$ & $0.423^{* *}$ & $0.205^{* *}$ \\
\hline$a_{23}$ & $0.220 * *$ & $0.200 * *$ & $0.213 * * *$ & $0.232^{* *}$ & $0.124^{*}$ \\
\hline$a_{24}$ & $0.196^{* *}$ & $0.453 * *$ & $0.431 * *$ & $0.321^{* *}$ & $0.372^{* *}$ \\
\hline$a_{2}$ & $0.227 * *$ & $0.380 * *$ & $0.502 * *$ & $0.405^{* *}$ & $0.409 * *$ \\
\hline \multicolumn{6}{|c|}{$\begin{array}{l}* \text { Correlation is significant at the } 0.05 \text { level (2-tailed) } \\
* * \text { Correlation is significant at the } 0.01 \text { level (2-tailed) } \\
* * * \text { Correlation is significant at the } 0.001 \text { level (2-tailed) }\end{array}$} \\
\hline
\end{tabular}


Table 6. Regression for psychological empowerment and organisational effectiveness

\begin{tabular}{|c|c|c|c|c|c|}
\hline Model & $\begin{array}{c}\text { Un-standardised } \\
\text { Co-efficient }\end{array}$ & Std. Error & $\begin{array}{c}\text { Standardised } \\
\text { Co-efficient }\end{array}$ & t- value & p-value \\
\hline$a_{21}$ & 0.140 & 0.049 & 0.140 & 2.882 & 0.004 \\
\hline$a_{22}$ & 0.094 & 0.043 & 0.108 & 2.170 & 0.031 \\
\hline$a_{23}$ & 0.321 & 0.046 & 0.369 & 7.032 & 0.000 \\
\hline$a_{24}$ & 0.134 & 0.053 & 0.155 & 2.514 & 0.012 \\
\hline
\end{tabular}

Table 7. Pearson's correlation coefficients between structural empowerment and organisational effectiveness

\begin{tabular}{|c|c|c|c|c|c|}
\hline & $a_{31}$ & $a_{32}$ & $a_{33}$ & $a_{34}$ & $a_{3}$ \\
\hline$a_{11}$ & $0.163^{* *}$ & $0.302^{* *}$ & $0.247^{* *}$ & $0.273^{* *}$ & $0.326^{* *}$ \\
\hline$a_{12}$ & $0.268^{* *}$ & $0.369^{* *}$ & $0.472 * *$ & $0.246^{* *}$ & $0.382^{* *}$ \\
\hline$a_{13}$ & $0.195^{* *}$ & $0.123^{*}$ & $0.211 * *$ & $0.408 * *$ & $0.303 * *$ \\
\hline$a_{14}$ & $0.216^{* *}$ & $0.232^{* *}$ & $0.197^{* *}$ & $0.501 * *$ & 0.420 ** \\
\hline$a_{15}$ & $0.167 * *$ & $0.135^{*}$ & $0.240^{* *}$ & $0.202 * *$ & $0.286^{* *}$ \\
\hline$a_{16}$ & $0.230^{* *}$ & $0.317 * *$ & $0.248^{* *}$ & $0.224 * *$ & $0.208 * *$ \\
\hline$a_{17}$ & $0.328 * *$ & $0.187^{* *}$ & $0.321 * *$ & $0.320 * *$ & $0.252 * *$ \\
\hline$a_{1}$ & $0.236^{* *}$ & $0.362 * *$ & $0.333^{* *}$ & $0.406^{* *}$ & $0.304 * *$ \\
\hline
\end{tabular}

Similarly, the moderating role of empowerment climate on the link between structural empowerment and organisational effectiveness for the favourable empowerment climate is presented in Table 12.

In an unfavourable climate, five out of seven components of structural empowerment do not significantly predict organisational effectiveness. Only the two components e.g. autonomy and reward system are found significant in the analysis. Similarly, in a favourable climate, all the variables are found to be significantly related and also result in a $28.2 \%$ variation in the organisational effectiveness in the present research. 
Table 8. Regression for structural empowerment \& organisational effectiveness

\begin{tabular}{|c|c|c|c|c|c|}
\hline Model $^{\mathrm{a}}$ & $\begin{array}{l}\text { Un-standardised } \\
\text { Co-efficient }\end{array}$ & Std. Error & $\begin{array}{c}\text { Standardised } \\
\text { Co-efficient }\end{array}$ & t- Value & p-Value \\
\hline$a_{11}$ & 0.141 & 0.044 & 0.043 & 3.205 & 0.000 \\
\hline$a_{12}$ & 0.247 & 0.086 & 0.096 & 2.872 & 0.000 \\
\hline$a_{13}$ & 0.410 & 0.176 & 0.109 & 2.330 & 0.020 \\
\hline$a_{14}$ & 0.916 & 0.217 & 0.282 & 4.226 & 0.000 \\
\hline$a_{15}$ & 0.228 & 0.066 & 0.072 & 3.455 & 0.000 \\
\hline$a_{16}$ & 0.417 & 0.182 & 0.138 & 2.283 & 0.023 \\
\hline$a_{17}$ & 0.217 & 0.059 & 0.070 & 3.678 & 0.000 \\
\hline
\end{tabular}

\section{DISCUSSION}

There is ample evidence in the previous studies that empowerment as an organisational practice is useful for the employees and the organisation as well. It is held that the employees with empowerment feeling have better job satisfaction (Spreitzer, et al 1997) and organisational commitment (Liden et al., 2000). Likewise, Koberg et al. (1999) also confirmed that the empowerment feelings were related to an enhanced level of work satisfaction and lesser chance of leaving the organisation. Thus, it is found that all the above studies held the idea that psychological empowerment achieved organisational effectiveness.

Moreover, in the present study, it is found that significant strong correlation between the perception of psychological empowerment and organisational effectiveness. The strongest correlation is demonstrated between the competence dimension and internal process model $(r=0.577, p<.001)$. As competence is the capacity of one's duties with requisite skills and the strength of this predictor is significant for causing psychological empowerment. Thus, a significant association between psychological empowerment and organisational effectiveness indicates that the former affects the later. Thus, the first hypothesis $\left(\mathbf{H}_{\mathbf{1}}\right)$ that a sense of psychological empowerment results in enhanced organisational effectiveness is supported. The details of the hypothesis and its result is presented in Table 13.

Similarly, the findings also suggest that 'structural empowerment' is strongly correlated to organisational effectiveness. This is proved by the correlation as well as regression analyses (Table 4-6). All the seven dimensions are positively and strongly correlated out of which the very strong correlation emerged in the case of autonomy $(\mathrm{r}=.420, \mathrm{p}<.001)$ and low level of correlation in case of reward system $(r=.206, p<.001)$ for overall organisational effectiveness. Moreover, a high correlation was demonstrated between autonomy $(\mathrm{r}=.501, \mathrm{p}<.001)$ and the open system model of organisational effectiveness followed by self-esteem and rational goal model ( $\mathrm{r}=.472, \mathrm{p}<.001)$. Thus, a strong relationship that exists between structural empowerment and organisational effectiveness implies that the former has a definite impact on the later. Hence, in the light of the above discussion, 
Table 9. Effects of psychological empowerment on organisational effectiveness under un-favourable empowerment climate

\begin{tabular}{|c|c|c|c|c|c|}
\hline Model $^{\mathbf{a}}$ & $\begin{array}{c}\text { Un-standardised } \\
\text { Co-efficient }\end{array}$ & Std. Error & $\begin{array}{c}\text { Standardised } \\
\text { Co-efficient }\end{array}$ & t- value & p-value \\
\hline$a_{21}$ & 0.149 & 0.126 & 0.067 & 1.188 & 0.236 \\
\hline$a_{22}$ & 0.282 & 0.112 & 0.147 & 2.530 & 0.012 \\
\hline$a_{23}$ & 0.124 & 0.119 & 0.064 & 1.045 & 0.297 \\
\hline$a_{24}$ & 0.295 & 0.137 & 0.154 & 2.151 & 0.032 \\
\hline \multicolumn{7}{|c|}{ a. Dependent Variable: organizational effectiveness. } \\
\hline
\end{tabular}

Table 10. Effects of psychological empowerment on organisational effectiveness under favourable empowerment climate

\begin{tabular}{|c|c|c|c|c|c|}
\hline Model $^{\mathbf{a}}$ & $\begin{array}{c}\text { Un-standardised } \\
\text { Co-efficient }\end{array}$ & Std. Error & $\begin{array}{c}\text { Standardised } \\
\text { Co-efficient }\end{array}$ & t- value & p-value \\
\hline$a_{21}$ & -0.957 & 0.066 & -0.533 & -14.552 & 0.044 \\
\hline$a_{22}$ & 2.776 & 0.135 & 1.786 & 20.510 & 0.031 \\
\hline$a_{23}$ & 1.857 & 0.067 & 1.422 & 27.882 & 0.023 \\
\hline$a_{24}$ & -4.286 & 0.133 & -2.897 & -32.171 & 0.020 \\
\hline \multicolumn{7}{|c|}{ a. Dependent Variable: organizational effectiveness. } \\
\hline
\end{tabular}

hypothesis $\left(\mathbf{H}_{2}\right)$ that structural empowerment is significantly related to organisational effectiveness is supported in the study.

Owing to the importance of favourable empowerment climate, it is pertinent to study the effect of empowerment climate on psychological empowerment. The empowerment climate was made a moderator to compare the effect of favourable climate from an unfavourable climate on psychological empowerment. The analyses show the regression figures in both the favourable and unfavourable empowerment. In an unfavourable empowerment climate, the overall model is significantly fit ( $p$ value $<.001$ ) as all the variables are significant and result in a $10.6 \%$ variation in the organisational effectiveness score. Two important components of psychological empowerment are not significant in predicting organisational effectiveness e.g. meaning and self-determination. This implies that unfavourable empowerment climate has no or little impact on meaning and self-determination and the other two components like competence and impact are highly affected.

Similarly, the analysis of data shows that in a favourable empowerment climate, the overall model is significantly fit ( $\mathrm{p}$-value $<.001)$. In other words, a favourable climate influences in strengthening psychological empowerment process that would lead to organisational effectiveness in the CPSEs. Hence, the above discussion regarding the research objective supports the hypothesis $\left(\mathbf{H}_{3}\right)$. 
Table 11. Effects of structural empowerment on organisational effectiveness under un-favourable empowerment climate

\begin{tabular}{|c|c|c|c|c|c|}
\hline Model $^{\mathrm{a}}$ & $\begin{array}{c}\text { Un-standardised } \\
\text { Co-efficient }\end{array}$ & Std. Error & $\begin{array}{c}\text { Standardised } \\
\text { Co-efficient }\end{array}$ & t- value & p-value \\
\hline$a_{11}$ & 0.131 & 0.211 & 0.040 & 0.621 & 0.535 \\
\hline$a_{12}$ & 0.251 & 0.157 & 0.099 & 1.603 & 0.110 \\
\hline$a_{13}$ & 0.421 & 0.235 & 0.113 & 1.794 & 0.074 \\
\hline$a_{14}$ & 0.886 & 0.219 & 0.274 & 4.047 & 0.000 \\
\hline$a_{15}$ & 0.224 & 0.197 & 0.071 & 1.135 & 0.257 \\
\hline$a_{16}$ & 0.394 & 0.184 & 0.131 & 2.144 & 0.033 \\
\hline$a_{17}$ & -0.195 & 0.212 & -0.063 & -0.923 & 0.357 \\
\hline
\end{tabular}

Table 12. Effects of structural empowerment on organisational effectiveness under favourable empowerment climate

\begin{tabular}{|c|c|c|c|c|c|}
\hline Model $^{\mathbf{a}}$ & $\begin{array}{c}\text { Un-standardised } \\
\text { Co-efficient }\end{array}$ & Std. Error & $\begin{array}{c}\text { Standardised } \\
\text { Co-efficient }\end{array}$ & t- value & p-value \\
\hline$a_{11}$ & 0.144 & 0.048 & 0.045 & 0.300 & 0.000 \\
\hline$a_{12}$ & 0.259 & 0.105 & 0.103 & 2.467 & 0.005 \\
\hline$a_{13}$ & 0.401 & 0.132 & 0.108 & 3.037 & 0.000 \\
\hline$a_{14}$ & 0.887 & 0.216 & 0.277 & 4.101 & 0.000 \\
\hline$a_{15}$ & 0.206 & 0.065 & 0.066 & 3.169 & 0.000 \\
\hline$a_{16}$ & 0.401 & 0.181 & 0.135 & 2.212 & 0.028 \\
\hline$a_{17}$ & \multicolumn{2}{|c|}{0.168} & 0.041 & 0.055 & 4.097 \\
\hline
\end{tabular}

Further, the analyses provide us the regression estimates in both the favourable and unfavourable empowerment climate. In an unfavourable empowerment climate, five out of seven components of structural empowerment did not significantly predict organisational effectiveness. Only the 
Table 13. Hypothesis testing

\begin{tabular}{|l|l|l|}
\hline \multicolumn{1}{|c|}{ Hypotheses } & \multicolumn{1}{|c|}{ Relations } & \multicolumn{1}{|c|}{ Result } \\
\hline $\mathrm{H}_{1}$ & $a_{2} \rightarrow a_{3}$ & Supported \\
\hline $\mathrm{H}_{2}$ & $a_{1} \rightarrow a_{2}$ & Supported \\
\hline $\mathrm{H}_{3}$ & $a_{2} \rightarrow a_{4} \rightarrow a_{3}$ & Supported \\
\hline $\mathrm{H}_{4}$ & $a_{1} \rightarrow a_{4} \rightarrow a_{2}$ & Supported \\
\hline
\end{tabular}

two components e.g., autonomy and reward system were significant in predicting organisational effectiveness. Similarly, in a favourable empowerment climate, all the components of structural empowerment significantly predict organisational effectiveness.

In other words, a favourable empowerment climate of trust, information sharing, cooperation and support, competitiveness, creativity, innovation, and proactive problem solving, etc. statistically influence in strengthening the structural empowerment process and which would ultimately lead to organisational effectiveness in the PSEs. Thus, the moderating role of a supportive empowerment climate is well established in influencing the structural components of empowerment in this case. Hence, the hypothesis $\left(\mathbf{H}_{4}\right)$ that the empowerment climate significantly influences structural empowerment in improving organisational effectiveness is supported.

\subsection{Limitations and Further Research}

The data collection for the study was confined only to some of the industrial establishments based in public sector. Constraints in some form or other were faced during the data collection process. To ensure more appropriateness in generalization, studies with a larger sample size could be undertaken. Moreover, the constructs of employee empowerment and organisational effectiveness were measured through some specific instruments developed by researchers in other cultural contexts. The present study was dependent on mostly quantitative aspects although qualitative aspects were not completely ignored. Therefore, the qualitative methodology should be equally applied. As the empowerment research related to public sector employees continues to be limited in scope, replication of this work with other types of organisations like government departments, public agencies, semi-government and private organisations might widen the generalisation of findings.

\section{CONCLUSION}

The sustainability of industrial establishments, by and large, are mostly contingent upon the degree of adoption of the innovative human resource practices which unequivocally focuses on maintaining human relations across the boundaries of the organisations. In short, human factor plays a critical role in sustainable business performance. To ensure congenial relations at the workplace, organisations make relentless efforts to empower employees and encourage their participation and involvement by optimally utilizing human resources. As the empowerment programmes are aimed at enhancing the level of communication, imparting appropriate training to the employees, and generating the opportunities for personal growth should be undertaken. For making the empowerment practices more effective, the organisations must make the employees understand the essence of the concept itself. Moreover, a trusting climate when coupled with empowerment programmes can significantly influence in enhancing effectiveness of the industrial establishments. Further, to achieve effectiveness, 
empowerment practices should embody transparent communication system facilitating the employees to share vital organisational information. There should be an atmosphere of promoting creativity and competitiveness amongst the employees at all levels and motivating subordinates for creative and proactive problem solving. Thus, the superiors should make their subordinates feel that a complete workplace empowerment climate prevails in the minds of the employees by way of taking periodic feedback and discussing with them about organisational strategies, plans and objectives. Similarly, the organisation should create and foster an enabling and supportive climate characterised by trust, openness, competitiveness, creativity and proactive problem-solving across its boundaries and at all levels of organisational hierarchy by way of preparing a meaningful and well understood mission statement, judicious allocation of resources amongst organisational members and providing a systematic approach for identifying business opportunities with a view to achieving sustainable competitive advantage. 


\section{REFERENCES}

Abdullah, M., \& Iqbal, S. (2020). The Dawn of Paternal HR: An Exploratory Study Using System Dynamics Approach. In Occupational Stress: Breakthroughs in Research and Practice (pp. 217-237). IGI Global.

Al-Kadeem, R., Backar, S., Eldardiry, M., \& Haddad, H. (2017). Review on using system dynamics in designing work systems of project organizations: Product development process case study. International Journal of System Dynamics Applications, 6(2), 52-70. doi:10.4018/JJSDA.2017040103

Alan, R. W. (1995). The leadership challenge of changing to a culture of empowerment. Executive Development, 8(1), 5-8. doi:10.1108/09533239510079482

Alexiev, A., Volberda, H., Jansen, J., \& Van Den Bosch, F. (2019). Contextualizing senior executive advice seeking: The role of decision process comprehensiveness and empowerment climate. Organization Studies. doi: $10.1177 / 0170840619830128$

Amor, A. M., Vázquez, J. P. A., \& Faíña, J. A. (2020). Transformational leadership and work engagement: Exploring the mediating role of structural empowerment. European Management Journal, 38(1), 169-178. doi:10.1016/j.emj.2019.06.007

Arslan Yürümezoğlu, H., \& Kocaman, G. (2019). Structural empowerment, workplace incivility, nurses' intentions to leave their organisation and profession: A path analysis. Journal of Nursing Management, 27(4), 732-739. doi:10.1111/jonm.12751 PMID:30656776

Auxilia, M., Raja, K., \& Kannan, K. (2020). Cloud-Based Access Control Framework for Effective Role Provisioning in Business Application. International Journal of System Dynamics Applications, 9(1), 63-80. doi:10.4018/IJSDA.2020010104

Ayala Calvo, J. C., \& García, G. M. (2018). Hardiness as moderator of the relationship between structural and psychological empowerment on burnout in middle managers. Journal of Occupational and Organizational Psychology, 91(2), 362-384. doi:10.1111/joop.12194

Chang, Y. Y. (2016). High-performance work systems, joint impact of transformational leadership, an empowerment climate and organizational ambidexterity. Journal of Organizational Change Management, 29(3), 424-444. doi:10.1108/JOCM-09-2015-0150

Chen, G., Kirkman, B. L., Kanfer, R., Allen, D., \& Rosen, B. (2007). A multilevel study of leadership, empowerment, and performance in teams. The Journal of Applied Psychology, 92(2), 331-346. doi:10.1037/00219010.92.2.331 PMID:17371082

Conger, J. A., \& Kanungo, R. N. (1988). The Empowerment Process: Integrating Theory and Practice. Academy of Management Review, 13(3), 471-482. doi:10.5465/amr.1988.4306983

Connolly, M., Jacobs, S., \& Scott, K. (2018). Clinical leadership, structural empowerment and psychological empowerment of registered nurses working in an emergency department. Journal of Nursing Management, 26(7), 881-887. doi:10.1111/jonm.12619 PMID:29675870

Dumblekar, V., \& Sharma, A. (2001). Leadership in banking sector. Indian Management, 19(9), 21-29.

Elharakany, R. A., Moscardini, A., Khalifa, N. M., \& Elghany, M. M. A. (2018). Modelling the Effect on Quality of Information and Communications Technology (ICT) facilities in Higher Education: Case Study_Egyptian Universities. International Journal of System Dynamics Applications, 7(3), 1-30. doi:10.4018/IJSDA.2018070101

Gözükara, İ., Çolakoğlu, N., \& Şimşek, Ö. F. (2019). Development culture and TQM in Turkish healthcare: Importance of employee empowerment and top management leadership. Total Quality Management \& Business Excellence, 30(11-12), 1302-1318. doi:10.1080/14783363.2017.1366266

Jordan, J. B., Streit, L. D., \& Binkley, J. S. (2003). Assessing and improving the effectiveness of national research laboratories. IEEE Transactions on Engineering Management, 50(2), 228-235. doi:10.1109/TEM.2003.810820

Kamble, S., Gunasekaran, A., \& Dhone, N. C. (2020). Industry 4.0 and lean manufacturing practices for sustainable organisational performance in Indian manufacturing companies. International Journal of Production Research, 58(5), 1319-1337. doi:10.1080/00207543.2019.1630772 
Kaur, G. (2013), A thesis on employee empowerment and organizational effectiveness: A comparative study of public, private and foreign banks in some North Indian states. Submitted to Thapar University, Punjab.

Koberg, C. S., Boss, W., Senjem, J. C., \& Goodman, E. A. (1999). Antecedents and outcomes of empowerment: Empirical evidence from the health care industry. Group \& Organization Management, 34(1), 71-91. doi:10.1177/1059601199241005

Kraimer, M. L., Seibert, S. E., \& Liden, R. C. (1999). Psychological empowerment as a multidimensional construct: A test of construct validity. Educational and Psychological Measurement, 59(1), 127-142. doi: $10.1177 / 0013164499591009$

Lee, H. W., \& Kim, E. (2020). Workforce diversity and firm performance: Relational coordination as a mediator and structural empowerment and multisource feedback as moderators. Human Resource Management, 59(1), 5-23. doi:10.1002/hrm.21970

Liden, R. C., Wayne, S. J., \& Sparrow, R. T. (2000). An examination of the mediating role of psychological empowerment on the relations between the job, interpersonal relationships, and work outcomes. The Journal of Applied Psychology, 85(3), 407-416. doi:10.1037/0021-9010.85.3.407 PMID:10900815

Lin, C. P., Liu, C. M., Liu, N. T., \& Huang, H. T. (2020). Being excellent teams: Managing innovative climate, politics, and team performance. Total Quality Management \& Business Excellence, 31(3-4), 353-372. doi:10. $1080 / 14783363.2018 .1427503$

Lin, M., Wu, X., \& Ling, Q. (2017). Assessing the effectiveness of empowerment on service quality: A multilevel study of Chinese tourism firms. Tourism Management, 61, 411-425. doi:10.1016/j.tourman.2017.03.001

Menon, S. T. (1999). Psychological empowerment: Definition, measurement, and validation. Canadian Journal of Behavioural Science, 31(3), 161-164. doi:10.1037/h0087084

Menon, S. T., \& Pethe, S. (2002), Organizational antecedents and outcomes of empowerment: Evidence from India. ISSWOV, Warsaw, Poland, Conference Proceedings, 289-293.

Priyadarshini, R., \& Venkatapathy, R. (2003). Organizational effectiveness in the banking industry. Indian Journal of Training and Development, 1(2), 109-121.

Quinn, R. E., \& Cameron, K. S. (1983). Organizational life cycles and shifting criteria of effectiveness: Some preliminary evidence. Management Science, 29(1), 33-51. doi:10.1287/mnsc.29.1.33

Quinn, R. E., \& Rohrbaugh, J. (1983). A spatial model of effectiveness criteria: Towards a competing values approach to organization analysis. Management Science, 29(3), 363-377. doi:10.1287/mnsc.29.3.363

Roseman, M. G., Mathe-Soulek, K., \& Krawczyk, M. (2017). The effect of psychological empowerment climate on restaurant food safety, food quality, and financial performance. Journal of Human Resources in Hospitality \& Tourism, 16(2), 137-152. doi:10.1080/15332845.2016.1202726

Sally, C. A. (2004). Does psychological empowerment mediate the relationship between psychological climate and job satisfaction. Journal of Business and Psychology, 18(4), 405-425.

Seibert, S. E., Silver, S. R., \& Randolph, W. A. (2004). Taking empowerment to the next level: A multiple-level model of empowerment, performance, and satisfaction. Academy of Management Journal, 47(3), 332-349.

Sharma, M., \& Kaur, G. (2011). Workplace empowerment and organisational effectiveness: An empirical investigation of the Indian banking sector. Academy of Banking Studies Journal, 10(2), 105-120.

Shukla, O. J., Jangid, V., Soni, G., \& Kumar, R. (2019). Grey Based Decision Making for Evaluating Sustainable Performance of Indian Marble Industries. International Journal of System Dynamics Applications, 8(2), 1-18. doi:10.4018/IJSDA.2019040101

Spreitzer, G. M. (1995). Psychological empowerment in the workplace: Dimensions, Measurement, and Validation. Academy of Management Journal, 38(5), 1442-1465.

Spreitzer, G. M. (1996). Social-structural characteristics of psychological empowerment. Academy of Management Journal, 39(2), 483-504. 
Spreitzer, G. M. (2007). Give peace a chance. Journal of Organizational Behavior, 28, 1077-1095. doi:10.1002/ job. 487

Suifan, T. S., Diab, H., Alhyari, S., \& Sweis, R. J. (2020). Does ethical leadership reduce turnover intention? The mediating effects of psychological empowerment and organizational identification. Journal of Human Behavior in the Social Environment, 30(4), 1-19. doi:10.1080/10911359.2019.1690611

Thomas, K. W., \& Velthouse, B. A. (1990). Cognitive elements of empowerment. Academy of Management Review, 15, 666-681.

Wang, J. L., Zhang, D. J., \& Jackson, L. A. (2013). Influence of self-esteem, locus of control, and organizational climate on psychological empowerment in a sample of C hinese teachers. Journal of Applied Social Psychology, 43(7), 1428-1435. doi:10.1111/jasp.12099

Zuñiga-Collazos, A., Castillo-Palacio, M., Montaña-Narváez, E., \& Castillo-Arévalo, G. (2020). Influence of managerial coaching on organisational performance. Coaching (Abingdon, UK), 13(1), 30-44. doi:10.1080/1 7521882.2019.1619795

Simanchala Das (b.1971) (PhD) is a dual doctorate in social science and management from Berhampur University, Odisha. He has a rich experience of 20 years in post graduate teaching and 3 years in research. He has quite a good number of publications in indexed journals both national and international. Moreover, he has contributed various book chapters and has authored 3 books with international publishers. He is a member of the Editorial Board for "Journal of Research Innovation and Management". He is a Life Member of International Society for Research and Development. His area of research interest includes employee empowerment and transformational leadership, cross cultural HRM. His teaching interests include organizational behavior, human resource management and performance management. Presently, he is working as Associate Professor at $K L$ Business School, Koneru Lakshmaiah Education Foundation (Deemed to be University), Vijayawada, Andhra Pradesh, India and is engaged in post-graduate teaching, research and consultancy activities.

Biswajit Acharjya holds B. Tech in Textile Engineering from College of Engineering and Technology, Biju Patnaik University of Technology, Odisha in 2010 and MBA (Finance and Marketing) from Utkal University, Odisha in 2015. He has submitted Ph. D. in management at VIT Business School, VIT, Vellore, India and currently working as Assistant Professor at KL Business School, Koneru Lakshmaiah Education Foundation (Deemed to be University), Vijayawada, Andhra Pradesh, India. Additionally, he has industrial experience as a textile engineer. His research interest includes computational intelligence and its application to behavioural finance in relation to exchange-traded funds. 